\title{
Respiratory Problems of Sands Carriers in the City of Lubumbashi/Rd Congo
}

\author{
Léon Kabamba Ngombe1,2, Nlandu Roger Ngatu' ${ }^{3}$, Nyembo Mukena Christophe1, \\ Benjamin Kabyla Ilunga ${ }^{3,4}$, Stanis Wembonyama Okitotsho ${ }^{4,5}$, \\ Jean-Baptiste Kakoma Sakatolo5, Oscar Luboya Numbi ${ }^{1,4,5}$, Brigitta Danuser6
}

${ }^{1}$ Department of Research, School of Nursing of Lubumbashi (ISTM Lubumbashi), Lubumbashi, Congo

${ }^{2}$ Faculty of Medicine, Department of Public Health, Unity of Toxicology, University of Kamina, Kamina, Congo

${ }^{3}$ Department of Environmental Medicine, Kochi University Medical School, Nankoku, Japan

${ }^{4}$ School of Public Health, Department of Public Health, University of Lubumbashi, Lubumbashi, Congo

${ }^{5}$ Faculty of Medicine, Department of Pediatry, University of Lubumbashi, Lubumbashi, Congo

${ }^{6}$ Service of Occupational Medicine, Institute for Work and Health, University of Lausanne and Geneva, Lausanne, Switzerland

Email: leonkab@hotmail.com

How to cite this paper: Ngombe, L.K., Ngatu, N.R., Christophe, N.M., Ilunga, B.K., Okitotsho, S.W., Sakatolo, J.-B.K., Numbi, O.L. and Danuser, B. (2016) Respiratory Problems of Sands Carriers in the City of Lubumbashi/Rd Congo. Open Access Library Journal, 3: e3172. http://dx.doi.org/10.4236/oalib.1103172

Received: October 25, 2016

Accepted: November 18, 2016

Published: November 21, 2016

Copyright $\odot 2016$ by authors and Open Access Library Inc.

This work is licensed under the Creative Commons Attribution International

License (CC BY 4.0).

http://creativecommons.org/licenses/by/4.0/

(c) (i) Open Access

\section{Abstract}

Objective: To determine the prevalence of respiratory symptoms and illustrate the dangerousness of the sands dust in the Artisanal carriers in the city of Lubumbashi, Katanga province, in the Democratic Republic of the Congo (DRC). Method: In total, 120 carriers of sand have been recruited in an exhaustive approach with 120 communal administrative officers of Lubumbashi city as control group. Respiratory symptoms were collected using a respiratory questionnaire. A multi-analysis varied with the test of logistic regression has been privileged to determine the association between the characteristics of the carriers and the respiratory symptoms. Results: The prevalence of respiratory symptoms reported in carriers of sands was greater than that of the control group for the symptoms such as: cough in the morning (52.5\% against $6.7 \%$ ), sputum in the morning (35\% against $7.5 \%$ ), shortness of breath after effort ( $18.3 \%$ against $5 \%)$, asthma (26.7\% against $5 \%)$, chronic bronchitis ( $12.5 \%$ against $4.2 \%$ ), rhinitis (62.5\% against $21.7 \%$ ), conjunctivitis (58.3\% against $17.5 \%)$. After adjustment, on factors such as age and education, the profession carrier of sands was strongly associated with the risk of developing respiratory symptoms below: spit in the morning, shortness of breath after effort, asthma, chronic bronchitis with a $p<0.001$. The Peak Expiratory Flow Rate (PEFR) has been significantly reduced in the Carriers of sands $(438.87 \pm 109.02)$ compared to controls $(480.14 \pm 70.73)(p<0.05)$. Conclusion: The profession carriers of sand as practiced in Lubumbashi, without means of adequate protection, 
carry a clear risk for respiratory health. It is essential to organize a specialized education in medicine of the work which can train doctors with proven expertise to address the enormous need for qualified personnel in this environment considered at risk of breathing.

\section{Subject Areas}

Epidemiology

\section{Keywords}

The Carriers, Prevalence, Dust of Sands, Respiratory Health

\section{Introduction}

Occupational exposure to dusts is a phenomenon well known especially in developing countries [1] [2]. The emissions of dust are high in the careers and in the manufacturing sector of the Bricks [3]. The development of our country has led many of changes including the evolution of the industrialization, of different means of transport and the existence of certain trades in several sectors not in conformity with the legislation. Rapid urbanization has led to an increase in the use of transport of the construction materials as a consequence an environmental pollution. The environmental program of the United Nations considers that 1.1 million people in the world breathe a polluted air [4]. This increases the number of deaths and hospitalizations per day in the world [5], because of its effects on human health [6] [7]. The exposure to these silica dusts is seen especially in the mines, quarries, the shipyards of the BTP who continue to practice unfortunately in a craft way in low-income countries. Present in any Congolese society, the carriers of the sands are drivers of trucks or trucks that carry the sands of quarries to the shipyards or the point of sale. During the process of loading and unloading of sands in the trucks or carts, it emerges from the large quantities of dust and the carriers are obliged to attend this process pollutant, often without measure of protection. Of this fact, the carriers of sand are in daily contact of various dust, including the silica, which is present in all the regions of the African continent [8]. Unlike other profession, during work years a dusty environment has the risk of inhalation of particles (silica) which may lead to different respiratory diseases [9] such as chronic bronchitis, emphysema, silicosis acute and chronic, cancer of the lung. According to Urom [10], the majority of respiratory symptoms found among workers in quarries were composed of non-productive cough, chest pain, catarrhs and dyspnoea. There are not a lot of epidemiological studies on the respiratory health of workers exposed to mineral dusts in the province of Katanga particularly among carriers of sands. As well, the purpose of this work is to determine the prevalence of respiratory symptoms and to illustrate the fatal effects of sands dust in the Artisanal carriers in the city of Lubumbashi/Katanga. 


\section{Materials and Methods}

\subsection{Study Population}

The present cross-sectional study was conducted in population of sands carriers in the city of Lubumbashi in Katanga. The population studied, is comprised of the carriers (Drivers of trucks and trucks of the sands) and a control group. In total, 150 carriers who have more than one year of seniority have been recruited and among them, only 120 have participated in the investigation of where the totality of 120 carriers. The control group is composed of 120 communal administrative officers of the Lubumbashi with more than one year of seniority with almost the same socio-economic level that the carriers. The City of Lubumbashi is the second largest city of the Democratic Republic of the Congo the most populated after Kinshasa, its population would be around two million inhabitants according to the latest estimates. It is the economic capital of the DRC. It is designated as the Copperbelt capital because of the production of the copper and is part of the Copper Belt of Africa [11]. This study was conducted in 2015 on a period of 2 months, from 1 June to 31 July 2015 in the 7 communes of Lubumbashi city. The size of the sample was a function of the number of carriers that we found on the place of service when our descent. As well there has been a exhaustive sampling to arrive to have all carriers of the sand of the Lubumbashi city each commune. Accordingly, the sample of our investigation was composed of 120 controls and 120 carriers of selected sand exhaustively.

\subsection{Methods}

The study analyzed the data: socio-anthropometric, respiratory symptoms and respiratory function using a questionnaire, physical examination. The workers have been consulted on their place of respective work. The information obtained concerning the health of sands carriers and controls have been collected on a respiratory health questionnaire including a general questionnaire on the sociodemographic characteristics (age, sex, educational level, alcohol, smoking habits, occupational history, seniority at work and exposures outside work), a questionnaire of the International Union Against Tuberculosis and Respiratory Diseases (IUATLD) Bronchial Symptoms (1986) [12], a questionnaire on the allergic rhinitis [13]. In addition, chronic bronchitis was defined according to the criteria of the WHO as a cough and sputum chronicles occurring at least three months per year for at least two years. We have considered as asthmatic, any subject having of paroxysmal crises of dyspnoea sibilante, of repeated episodes of wheezing in the chest or a spasmodic cough with respiratory discomfort to repetition. Of rhinitis have been defined on the basis of a quantitative score SFAR (Score for allergic rhinitis) [13]. The Ocular pruritus, redness of the eyes and the watery symptoms were sought to define the conjunctivitis. The weight was measured by means of a balance calibrated and verified, and the size was also measured with a spacer. The recording of the blood pressure by means of an electronic device (OMRON Hem8402) was carried out at the left arm argued to the height of the heart. The topic is being rested for at least 15 minutes in a seated position. 


\subsection{Approval of the Ethics Committee}

The informed consent of sands carriers was obtained from the latter. Our study has received the approval of the ethics committee of the University of Lubumbashi for its conduct.

\subsection{Data Analyzes}

All analyzes were performed using the SPSS software 21.0 (SPSS Inc., Chicago, IT, USA). The statistical study was based on the analysis of the variance and the test " $T$ " of the student for the comparison of the averages and proportions. For the qualitative variables, it was based on the study of Chi square with or without correction of Yates. The threshold of significance chosen corresponded to a $p$ value $<0.05$. On the other side, to determine the association between the characteristics of the carriers of sand and respiratory symptoms reported, a multi analysis varied with the test of logistic regression was advantaged. The model had estimated the strength of the Association by a report of prevalence (OR) and its $95 \%$ confidence interval (C.I.95\%). The threshold of significance chosen corresponds to a value of $p<0.05$.

\section{Results}

\subsection{Anthropometric Characteristics and Socio-Demographic of Carriers}

Table 1 shows that the study sample is composed of 120 carriers of sands and 120 con-

Table 1. Sociodemographic parameters.

\begin{tabular}{ccc}
\hline Characteristics of Subjects & $\begin{array}{c}\text { Sands carriers } \\
(\mathbf{n}=120)\end{array}$ & $\begin{array}{c}\text { Controls } \\
(\mathbf{n}=120)\end{array}$ \\
\hline $\begin{array}{c}\text { Anthropometric parameters, clinical, } \\
\text { demographic, and those related to the work } \\
\text { Age (years) }\end{array}$ & Average +/- DS & Average +/- DS \\
BMI (kg/cm $\left.{ }^{2}\right)$ & $33.67 \pm 8.55$ & $32.63 \pm 7.90$ \\
Duration of work & $22.87 \pm 2.66$ & $23.23 \pm 3.61$ \\
Seniority & $10.35 \pm 1.77$ & $10.3 \pm 2.02$ \\
PAS & $4.8 \pm 2.73$ & $5.76 \pm 3.05 \#$ \\
PAD & $119 \pm 9.99$ & $125.9 \pm 17.19 \#$ \\
DEP (L/s) & $73.33 \pm 9.28$ & $73.87 \pm 12.17$ \\
Tobacco & $438.87 \pm 109.02$ & $480.14 \pm 70.73 \#$ \\
Alcohol & $77(81.9)^{*}$ & $17(18.1)$ \\
Education & $84(83.2)^{*}$ & $17(16.8)$ \\
Primary-Secondary & & $61(50.8)$ \\
A graduate & $103(85.8)^{*}$ & $59(49.2)^{\star}$ \\
Lung Auscultation & $17(14.2)$ & $119(99.17)^{*}$ \\
Pathological & &
\end{tabular}

${ }^{\star}$ Notes: \#, the value of $p$ less than to 0.01 for the test " $\mathrm{t}$ " of student; ${ }^{*}, p$ value less to 0.001 for the Fisher exact test. 
trols to which the average age was $33.67 \pm 8.55$ and $32.63 \pm 7.9$ among carriers and controls, respectively. For the carriers, the seniority was $4.8 \pm 2.73$ years, whereas it was $5.76 \pm 3.05$ years among the controls. The duration of work was of $10.35 \pm 1.75$ hours/day among the carriers against $10.3 \pm 2.02$ hours/day among the controls. The body mass index of carriers was of $22.87 \pm 2.66$ against $23.23 \pm 3.61$ among the control group. With respect to education, $85.8 \%$ of the carriers had a level of primary study against $50.8 \%$ of controls. Among carriers, $83.2 \%$ were taking of alcohol against $16.8 \%$ of controls. For the tobacco, it was found that $81.9 \%$ of carriers were smokers against $18.1 \%$ in the control group. The review of the chest has revealed that $26.67 \%$ of carriers of sand have had a pathological lung auscultation compared to $0.83 \%$ in the control group. The peak expiratory flow of Sand carriers was reduced in a significant way by report to the control group $(438.87 \pm 109.02$ against $480.14 \pm 70.73)(p<0.05)$.

\subsection{Prevalence of Respiratory Symptoms}

This Table 2 shows the prevalence of respiratory symptoms in the Carriers of sands and the control group. The carriers have submitted a prevalence of cough in the morning of 2.63 times more, a prevalence of sputum each morning from 1.99 times more, a prevalence of shortness of breath after effort of 1.7 times more, a prevalence of asthma of 1.93 times more, a prevalence of chronic bronchitis of 1.57 times more, a prevalence of rhinitis 2.29 times more, a prevalence of conjunctivitis of 2.29 times more compared to the control group. The prevalence of wheezing was 0.74 times more among the carriers of the sands without significant difference compared to the control group.

\subsection{Multi Analysis Varied with the Test of Logistic Regression}

Table 3 reveals that after adjustment, there is an association between all respiratory symptoms and the profession of sands carriers. In effect, the tobacco has been associated with the presence of sputum each morning ( $\mathrm{OR}=2.59)$, asthma $(\mathrm{OR}=4.6)$. In addition, alcohol has also been associated with the shortness of breath after effort (OR $=0.28)$ and asthma $(\mathrm{OR}=0.29)$.

Table 2. Prevalence of respiratory symptoms, with the corresponding risk, in function of the profession.

\begin{tabular}{ccccc}
\hline Respiratory symptoms & $\begin{array}{c}\text { carriers of Sand } \\
\mathbf{N}=120(\%)\end{array}$ & $\begin{array}{c}\text { Controls } \\
\mathbf{N}=120(\%)\end{array}$ & RP IC [95\%] & $p$ \\
\hline Wheezing & $6(5)$ & $7(5.8)$ & $0.74[0.39-1.40]$ & 0.77 \\
Cough In the morning & $63(52.5)$ & $8(6.7)$ & $2.63[2.09-3.30]$ & $<0.001$ \\
Sputum in the morning & $42(35.0)$ & $9(7.5)$ & $1.99[1.61-2.47]$ & $<0.001$ \\
Shortness of breath after effort & $22(18.3)$ & $6(5.0)$ & $1.7[1.33-2.16]$ & 0.002 \\
Asthma & $32(26.7)$ & $6(5)$ & $1.93[1.57-2.38]$ & $<0.001$ \\
Chronic bronchitis & $15(12.5)$ & $5(4.2)$ & $1.57[1.18-2.09]$ & 0.03 \\
Rhinitis & $75(62.5)$ & $26(21.7)$ & $2.29[1.76-2.99]$ & $<0.001$ \\
Conjunctivitis & $70(58.3)$ & $21(17.5)$ & $2.29[1.78-2.95]$ & $<0.001$ \\
\hline
\end{tabular}

RP: prevalence ratio, IC: Confidence interval, the values of $p$ indicate the levels of meanings $(p<0.05$ : significant difference). 
Table 3. Association between the characteristics of the carriers of sand and respiratory symptoms with the test of logistic regression with adjustment for age and level of education.

\begin{tabular}{|c|c|c|c|c|c|}
\hline \multirow[t]{2}{*}{ Variable } & Sputum/Morning & $\begin{array}{c}\text { Shortness of breath } \\
\text { after effort }\end{array}$ & Asthma & Chronic bronchitis & Rhinitis \\
\hline & OR \& IC [95\%] & OR \& IC [95\%] & OR \& IC [95\%] & OR \& IC [95\%] & OR \& IC [95\%] \\
\hline \multicolumn{6}{|l|}{ Age } \\
\hline$<40$ & $1.17[0.44-3.13]$ & $0.25[0.09-0.68]$ & $0.89[0.30-2.62]$ & $0.77[0.19-3.13]$ & $0.94[0.41-2.18]$ \\
\hline$>41$ & 1 & 1 & 1 & 1 & 1 \\
\hline \multicolumn{6}{|l|}{ Duration of work } \\
\hline$\leq 10$ & $1.15[0.57-2.33]$ & $1.31[0.53-3.21]$ & $1.97[0.86-4.51]$ & $2.58[0.86-7.69]$ & $0.76[0.42-1.39]$ \\
\hline$>10$ & 1 & 1 & 1 & 1 & 1 \\
\hline \multicolumn{6}{|l|}{ Age (years) } \\
\hline$\leq 5$ & $1.02[0.51-2.04]$ & $1.18[0.49-2.85]$ & $1.56[0.69-3.49]$ & $1.05[0.38-2.86]$ & $1.38[0.76-2.49]$ \\
\hline$>5$ & 1 & 1 & 1 & 1 & 1 \\
\hline \multicolumn{6}{|l|}{ Tobacco } \\
\hline Yes & $0.72[0.29-1.78]$ & $0.28[0.09-0.87]^{\star}$ & $0.29[0.09-8.3]^{*}$ & $0.3[0.08-1.17]$ & $1.07[0.49-2.35]$ \\
\hline Non & 1 & 1 & 1 & 1 & 1 \\
\hline \multicolumn{6}{|l|}{ Category } \\
\hline Carrier & $6.76[2.55-17.9] \#$ & $6.82[2.13-21.9] \#$ & $8.48[2.75-26.15] \#$ & $8.15[2.19-30.27] \#$ & $6.07[2.84-12.95] \#$ \\
\hline Control & 1 & 1 & 1 & 1 & 1 \\
\hline \multicolumn{6}{|l|}{ Education } \\
\hline Primaire-Secondaire & $0.53[0.22-1.3]$ & $0.69[0.23-2.01]$ & $0.74[0.26-2.07]$ & $0.31[0.09-1]$ & $0.77[0.38-1.55]$ \\
\hline Diploma & 1 & 1 & 1 & 1 & 1 \\
\hline
\end{tabular}

${ }^{*}$ Notes: $\&$, adjusted odds ratio; IC, confidence interval; ${ }^{*}$, the value of $p$ adjusted less than 0.05 ; \#, $p$ Value Adjusted less than 0.001.

\subsection{Correlation Test}

In Table 4, a correlation has been found between each of the 2 parameters cardio-respiratory (DEP, SBP) and the profession carriers of sand. In effect, a correlation has been found between the DEP and tobacco. The seniority has been correlated with the peak expiratory flow rate and systolic blood pressure. Concerning alcohol and tobacco, a correlation has been found with the diastolic blood pressure $(p<0.05)$.

\section{Discussion}

The professional environment of the Sands carriers is the same as that of the quarries of the sands or stones characterized by the presence of a large quantity of dust containing silica free. This study finds that $100 \%$ of workers have not of material for personal protection and do not use some means or strategies for the prevention of silico-tuberculosis and other respiratory problems in the exercise of their profession. Our finding is not different from that fact by Aliyu [14] in the north of Nigeria and by Yadav [15] to India in the careers of the stones. The lack of use of the materials and of the means of protection of our sands carriers could be at the bottom level of instruction. This is consistent with the finding of Hentschel [16] which has found that most of the workers of the artisanal mining had not of education and had a level socio economic bottom. 
Table 4. Association between the characteristics of the carriers of sand and the respiratory parameter (peak flow) and the blood pressure with the test of Pearson Correlation.

\begin{tabular}{|c|c|c|c|}
\hline Variable & DEP & SBP & DBP \\
\hline \multicolumn{4}{|l|}{ Age } \\
\hline$>41$ & 1 & & \\
\hline \multicolumn{4}{|l|}{ Duration of work } \\
\hline \multicolumn{4}{|l|}{ Age (years) } \\
\hline$\leq 5$ & $0.127[0.05]$ & $0.167[0.01]$ & $0.11[0.08]$ \\
\hline$>5$ & 1 & & \\
\hline \multicolumn{4}{|l|}{ Tobacco } \\
\hline Yes & $0.173[0.007]$ & $0.08[0.18]$ & $-0.190[0.003]$ \\
\hline Non & 1 & & \\
\hline \multicolumn{4}{|l|}{ Category } \\
\hline Carrier & $0.219[0.001]$ & $0.069[<0.0001]$ & $0.025[0.69]$ \\
\hline Control & 1 & & \\
\hline \multicolumn{4}{|l|}{ Education } \\
\hline Primaire-Secondaire & $0.04[0.49]$ & $0.03[0.61]$ & $-0.047[0.466]$ \\
\hline Diplôma & 1 & & \\
\hline
\end{tabular}

*Notes: $p$, correlation coefficient; PEFR, Peak Expiratory Flow; SBP, systolic blood pressure; DBP, diastolic blood pressure.

Our study reveals that the carriers of sand handle on a daily basis, without rest, all days during more than 10 hours of large quantities of sand without means of protection is individual or collective. Our study has also found prevalence significantly elevated respiratory symptoms among carriers by report to the non-exposed group. The respiratory symptoms collected by the examination revealed the presence of a large number of complaints among carriers, and this in a meaningful way compared to the control group, with a predominance of respiratory signs such as cough (52.5\%), crisis of shortness of breath after effort (18.3\%), the sputum each morning (35.0\%), chronic bronchitis $(12.5 \%)$, asthma $(26.7 \%)$, rhinitis $(62.5 \%)$, conjunctivitis $(58.3 \%)$. In effect, our results are comparable to those found by other authors [17] [18] [19]. The prevalence of shortness of breath after effort and wheezing was lower than in relation to the results of the studies made by Abdel-Rasoul [20], Singh [21], Nurul [22] and Singh [23]. Our survey shows a risk of chronic bronchitis manifest with a prevalence of $12.5 \%$. This rate is lower than that found by some authors [24] [25]. The prevalence of asthma found in this work was to $26.7 \%$ among exposed, far exceeding that reported by Bonny [25] and Chun-Yang [24]. Moreover, our study has registered $26.67 \%$ of respiratory abnormality to the lung auscultation of the exposed subjects. This result is consistent with the respiratory symptoms found in this population. Currently, it is known that an exposure to 
dust cause of dermatitis and affects the health [26] of the population as well as of workers.

After adjustment for age and education in the model, our study found a strong association between the profession and respiratory symptoms such as: spit in the morning, shortness of breath after effort, asthma, chronic bronchitis and rhinitis. In effect, the unhealthy environment and poor conditions of work of carriers of sand could explain this association. In our study, tobacco is strongly associated with spitting in the morning and to asthma. This is consistent with several studies which show that the use of tobacco and/or drugs can have an aggravator effect on the respiratory pathologies of subjects exposed to dust [27] [28]. This study involves a few weaknesses. The choice of the control group may be questioned. Normally, the unexposed subjects should be selected in the same place of work that the exposed subjects. The effect of the inherent healthy worker to the transverse epidemiological model constitutes a bias and another weakness of our study. Because, it can also lead to under estimate in our study the prevalence of clinical symptoms and the importance of the occupational risk in general. It is significant that these small businesses are known by the Congolese government to apply the occupational medicine as well as the compliance with the standards required in the Labor Code Congolese in the matter of exposure of occupational origin. The RD Congo are struggling to reduce air pollution and do not have wide studies concerning admissions to the hospital caused by atmospheric particles because the majority of the population does not have access to the best health care. It will be essential to conduct the cohort studies in the future.

\section{Conclusion}

This study reveals the poor conditions of work and the lack of protective equipment to staff of the carriers of Congolese sands. In the majority of cases, the respiratory symptoms of carriers could be in direct relationship with their profession by report to the control group. It is essential to develop a service of Medicine of work in order to ensure a purely technical and medical environment considered truly at risk of breathing.

\section{References}

[1] Aigbedion, I. and Iyayi, S. (2007) Environmental Effect of Mineral Exploitation in Nigeria. International Journal of Physical Sciences, 2, 33-38.

[2] Fatusi, A. and Erbabor, G. (1996) Occupational Health Status of Sawmill Workers in Nigeria. Journal of the Royal Society of Health, 116, 232-236. https:/doi.org/10.1177/146642409611600408

[3] Olusegun, O., Adeniyi, A. and Adeola, G.T. (2009) Impact of Granite Quarrying on the Health of Workers and Nearby Residents in Abeokuta Ogun State, Nigeria. Ethiopian Journal of Environmental Studies and Management (EJESM), 2, 21-26. https:/doi.org/10.4314/ejesm.v2i1.43497

[4] Jansen, M., Qian, J., Wojciechowska-Shibuya, M., et al. (Eds.) (2002) Environmental Threats to Children. In: Children in the New Millennium Environmental Impact on Health, United Nations Environmental Program, Children's Fund and World Health Organization, 
43-86.

[5] Zanobetti, A. and Schwartz, J. (2001) Are Diabetics More Susceptible to the Health Effects of Air Terminal Particles? American Journal of Respiratory and Critical Care Medicine, 164, 831-833. https:/doi.org/10.1164/ajrccm.164.5.2012039

[6] Pope, C.A.III, Burnet, R.T., Thun, M.J., et al. (2002) Lung Cancer, Cardiopulmonary Mortality, and Long Term Exposure to Fine Particulate Air Pollution. JAMA, 287, 1132-1141.

[7] Epton, M.J., Drawson, R., Brooks, W.M., et al. (2008) The Effect of Ambient Air Pollution on Respiratory Health of School Children: A Panel Study. About Health, 7, 16.

[8] Leclerc, J.C. (1945) Structure and Relief of the West Africa. Rhodaniennes Studies, 20, 149172. https:/doi.org/10.3406/geoca.1945.6598

[9] Park, K. (2007) Occupational Health. In: Park's Textbook of Preventive and Social Medicine. 18th Edition, m/s Banarsidas Bhanot, Jabalpur, 608-610.

[10] Urom, S.E., Antai, A.B. and Osim, E.E. (2004) Symptoms and Lung Function Values in Nigerian Men and Women Exposed to Dust Generated from Crushing of Granite Rocks in Calabar, Nigeria. Nigerian Journal of Physiological Science, 19, 41-47.

[11] Lubumbashi (Congo) Report from Wikipedia. (In French) http://fr.wikipedia.org/wiki/Lubumbashi

[12] Burney, P.G., Laitinen, P.S., Huckauf, H., Tattersfield, A.E., Chinn, S., et al. (1989) Validity and Repeatability of the IUATLD (1984) Bronchial Symptoms Questionnaire: International Year Comparison. European Respiratory Journal, 2, 940-945.

[13] Annesi-Maesano, I., Didier Was, K.M., Chanal, I., Moreau, D. and Bousquet, J. (2002) The Score for Allergic Rhinitis (SFAR): A Simple and Valid Assessment Method in Population Studies. Allergy, 57, 107-114. https:/doi.org/10.1034/j.1398-9995.2002.103170.x

[14] Aliyu, A.A. and Shehu, A. (2006) Occupational Hazards and Safety Measures among Stone Quarry Workers in northern Nigerian. Nigerian Medical Practitioner, 50, 42-47.

[15] Yadav, S.P., Anand, P.K. and Singh, H. (2011) Awareness and Practices about Silicosis among the Sandstone Quarry Workers in Desert Ecology of Jodhpur, Rajasthan, India. Journal of Human Ecology, 33, 191-196.

[16] Hentschel, T., Hruschka, F. and Priester, M. (2002) Global Report on Artisanal and Small Scale Mining. Mining, Minerals and Sustainable Development Project, Working Paper 70, 3.

[17] Mashaallah, H., Mohammad, R.Z. and Ali, A.F. (2006) Prevalence of Silicosis among Workers in Stone-Cutter and Silica Powder Production Factories. Tanaffos, 5, 31-36.

[18] Lemele, H., Araujo, A.J., et al. (1994) Respiratory Symptoms and Spirometric Tests of Quarry Workers in Rio de Janeiro. Revista da Associação Médica Brasileira, 40, 23-35.

[19] Nwibo, A., Ugwuj, E.I., Nwambeke, N., Emelumadu, O.F. and Ogbonnaya, L.U. (2012) Pulmonary Problems among Quarry Workers of Stone Crushing Industrial Site at Umuoghara, Ebonyi State, Nigeria. International Journal of Occupational and Environmental Medicine, 3, 178-185.

[20] Abdel-Rasoul, G.M., Mahrous, O.A.E., Abu Salem, M., Al-Batanony, M.A. and Llam, H.K. (2009) Auditory and Respiratory Health in an Iron and Steel Factory. Zagazig Journal of Occupational Health and Safety, 2, 1-10. https:/doi.org/10.2486/josh.2.1

[21] Singh, P.L., Bhardwaj, H. and Deepak, K.K. (2013) Occupational Exposure to Respirable Suspended Particulate Matter and Lung Functions Deteriorationamong Steel Workers: An Exploratory Study in India. ISRN Public Health, 2013, Article ID: 325410. https:/doi.org/10.1155/2013/325410 
[22] Hamzah, N.A., Mohd Tamrin, S.B. and Ismail, N.H. (2013) Metal Dust Exposure and Respiratory Symptoms among Steel Workers: A Dose-Response Relationship. International Journal of Collaborative Research on Internal Medicine \& Public Health, 7, 24-39.

[23] Singh, P.L., Bhardwaj, H. and Deepak, K.K. (2011) Respirable Suspended Particulate Matter (MPUB) and Respiratory Symptoms among Casting Industry Workers: An Exploratory Study in Northern India. International Journal of Advanced Engineering Technology, 2, 251-259.

[24] Pozzoli, T., Massola, H., Magni, C., Angelini, E. and Capodaglio, E. (1979) Dusting and Risky of Silicosis in the Cement Industry. Medicina del Lavoro, 70, 195-202.

[25] Bonny, J.S., Pigearias, B., Lonsdorfer, J., Cantineau, H. and Curtes, J.P. (1988) Respiratory Diseases and Ventilatory Function among Workers of a Cement Plant in Abidjan (Cote d'Ivoire). Arch evil Prof, 49, 455-460.

[26] World Health Organization (1999) Prevention and Control Exchange: Hazard Prevention and Control in the Work Environment. WHO, Geneva, 219.

[27] Ulm, K., Gerein, P., Eigenthaler, I., Schmidt, S. and Ehnes, H. (2004) Silica, Silicosis and Lung-Cancer: Results from a Cohort Study in the Stone and Quarry Industry. International Archives of Occupational and Environmental Health, 77, 313-318. https:/doi.org/10.1007/s00420-004-0513-6

[28] Ulm, K., Waschulzik, B., Ehnes, H., Guldner, K., Thomasson, B., Schwebig, A., et al. (1999) Silica Dust and Lung Cancer in the German Stone, Quarrying, and Ceramics Industries: Results of Acase-Control Study. Thorax, 54, 347-351. https:/doi.org/10.1136/thx.54.4.347

\section{Submit or recommend next manuscript to OALib Journal and we will provide best service for you:}

- Publication frequency: Monthly

- 9 subject areas of science, technology and medicine

- Fair and rigorous peer-review system

- Fast publication process

- Article promotion in various social networking sites (LinkedIn, Facebook, Twitter, etc.)

- Maximum dissemination of your research work

Submit Your Paper Online: Click Here to Submit

Or Contact service@oalib.com 